\title{
Carsten Gerner-Beuerle
}

\section{Algorithmic Trading and the Limits of Securities Regulation}

\begin{abstract}
Since the infamous flash crash of 2010, instances of unexplained high volatility in financial markets, often driven by algorithmic and high-frequency trading, have received increased attention by policy makers and commentators. A number of regulatory initiatives in the EU and US deal specifically with the perceived risks that algorithmic and high-frequency trading pose to market quality. However, their efficacy is disputed, with some claiming that they are unlikely to prevent the future misuse of HFT practices, while others caution that the additional regulatory burden may have unintended and counterproductive consequences for market efficiency. This paper examines whether existing regulatory techniques, notably disclosure, internal testing and monitoring systems, and the regulation of structural features of the trade process, such as order execution times and circuit breakers, are adequate to address the risk of extreme market turbulence. It draws on market microstructure theory in arguing that regulation in the EU and the US takes in sufficient account of the mechanics of automated trading in modern financial markets.
\end{abstract}

\section{Table of Contents}

1 Introduction $\mathbf{1 0 9}$

2 Algorithmic Trading and Unintended Consequences — 114

2.1 Types of Trading Algorithm 114

2.2 Price Effects - 116

3 Regulatory Solutions 121

3.1 Disclosure and Internal Risk Control Systems

3.2 Circuit Breakers 125

3.2.1 Circuit Breakers around the World 125

3.2.2 Efficiency of Circuit Breakers - 130

3.3 Auction Design — 137

4 Conclusion 139

Carsten Gerner-Beuerle, Faculty of Laws, University College London, Email: c.gerner@ucl.ac.uk. I am grateful to the participants of workshops at the University of Helsinki and the UCL Department of Computer Science for helpful comments and suggestions. Special thanks are due to Emilios Avgouleas, Guido Germano and Heikki Marjosola. All remaining errors are mine. 


\section{Introduction}

According to some calculations, high frequency trading now accounts for more than $50 \%$ of trading volume in US equity markets, $40 \%$ in European equity markets, and between $60 \%$ and $80 \%$ in futures markets. ${ }^{1}$ Algorithmic trading, of which high-frequency trading is a special case, ${ }^{2}$ is responsible for the clear majority of trades in many markets. ${ }^{3}$ As algorithmic and high frequency trading have proliferated, so have the regulatory initiatives to address their perceived harmful consequences. Algorithms have been held responsible for sudden violent market movements that have become frequent since the mid-1990s, ${ }^{4}$ such as the infamous "flash crash" of May 2010.5 They, or at least certain types of

1 Thierry Foucault/Sophie Moinas, "Is Trading Fast Dangerous?” in Walter Mattli (ed.), Global Algorithmic Capital Markets: High Frequency Trading, Dark Pools, and Regulatory Challenges (OUP 2019); Rena S. Miller/Gary Shorter, High Frequency Trading: Overview of Recent Developments, Congressional Research Service Report (2016), 1. For more detailed data that reports significant variation across EU trading venues, see also Steffen Kern/Giuseppe Loiacono, High Frequency Trading and Circuit Breakers in the EU: Recent Findings and Regulatory Activities, in Mattli, Ibid. at 308, 312.

2 Algorithmic trading is defined by the Markets in Financial Instruments Directive (Directive 2014/65/EU of the European Parliament and of the Council of 15 May 2014, [2014] OJ L173/349 (MiFID II)) as "trading in financial instruments where a computer algorithm automatically determines individual parameters of orders such as whether to initiate the order, the timing, price or quantity of the order or how to manage the order after its submission, with limited or no human intervention”, MiFID II, Art 4(1), subsection (39). High-frequency trading is an algorithmic trading strategy that makes use of infrastructure intended to minimise network and other types of latencies, for example co-location, proximity hosting or high- speed direct electronic access; generates, routes and/or executes orders without human intervention; and the algorithmic trader has a high message intraday rate as regards orders, quotes or cancellations, MiFID II, Art 4(1), subsection (40). An intraday message rate is regarded as high if two or more messages per second are submitted with respect to a single financial instrument or four or more messages per second with respect to all financial instruments traded on a trading venue, Commission Delegated Regulation (EU) 2017/565 of 25 April 2016 supplementing Directive 2014/65/EU of the European Parliament and of the Council as regards organisational requirements and operating conditions for investment firms and defined terms for the purposes of that Directive, [2017] OJ L 87/1, Art 19(1).

3 Yesha Yadav, "How Algorithmic Trading Undermines Efficiency in Capital Markets" (2015) 68 Vand. L. Rev. 1607, 1619.

4 Irene Aldridge/Steven Krawciw, Real-time risk: what investors should know about fintech, high-frequency trading, and flash crashes (Wiley 2017), 111.

5 For a comprehensive analysis of the flash crash of May 2010, see Commodity Futures Trading Commission (CFTC) and Securities / Exchange Commission (SEC), Findings regarding the market events of May 6, 2010 (September 2010). Discussions of the causes of the flash crash from the 
high frequency traders, have been criticised for reducing liquidity, ${ }^{6}$ expending valuable resources on a socially wasteful "arms race" with the goal of reducing latency by a matter of milliseconds, ${ }^{7}$ and placing other investors at a persistent informational disadvantage similar to traditional insiders who exploit inside information. ${ }^{8}$

However, there are probably few regulatory initiatives that stand on weaker theoretical and empirical ground than the requirements imposed on algorithmic and high frequency traders in the EU's Markets in Financial Instruments Directive (MiFID II) ${ }^{9}$ or Regulation NMS - Regulation of the National Market System in the United States. ${ }^{10}$ Empirical evidence shows predominantly that algorithmic and high frequency trading have, under most circumstances, positive effects on market quality and price formation. ${ }^{11}$ Regulatory interference with the trading

literature include Eric M. Aldrich/Joseph A. Grundfest/Gregory Laughlin, "The Flash Crash: A New Deconstruction” (2017), available at SSRN: https://ssrn.com/abstract=2721922; David Easley/Marcos M. López de Prado/Maureen O'Hara, "The Microstructure of the "Flash Crash": Flow Toxicity, Liquidity Crashes and the Probability of Informed Trading” (2011) 37 J. Portf. Manag. 118; Andrei Kirilenko/Albert S. Kyle/Mehrdad Samadi/Tugkan Tuzun, "The Flash Crash: High-Frequency Trading in an Electronic Market" (2017) 72 J. Fin. 967.

6 Andrei A. Kirilenko/Andrew W. Lo, "Moore's Law versus Murphy's Law: Algorithmic Trading and Its Discontents” (2013) 27 J. Econ. Perspect. 51, 60.

7 Eric Budish/Peter Cramton/John Shim, "The High-Frequency Trading Arms Race: Frequent Batch Auctions as a Market Design Response” (2015) 130 Q. J. Econ. 1547. This issue has been popularised by Michael Lewis, Flash Boys: A Wall Street Revolt (W.W. Norton 2014).

8 Yesha Yadav, "Insider Trading and Market Structure" (2016) 63 UCLA L. Rev. 968.

9 Directive 2014/65/EU (fn. 2).

1017 CFR $\S \S 242.600$ - 242.613, promulgated by the SEC pursuant to Section $11 \mathrm{~A}$ of the Securities Exchange Act of 1934. For a critical assessment of Regulation NMS, see Jennifer V. Dean, "Paradigm Shifts / Unintended Consequences: The Death of the Specialist, the Rise of High Frequency Trading, / the Problem of Duty-Free Liquidity in Equity Markets” (2012) 8 FIU L. Rev. 217; Paul G. Mahoney, "Equity Market Structure Regulation: Time to Start Over" (2020), Virginia Law and Economics Research Paper No. 2020 -11, available at SSRN: https://ssrn.com/abstract=3622291; Steven McNamara, "The Stock Exchange as Multi-Sided Platform and the Future of the National Market System” (2018) BYU L. Rev. 969.

11 Jonathan Brogaard/Terrence Hendershott/Ryan Riordan, "High-frequency trading and price discovery” (2014) 27 Rev. Financ. Stud. 2267; Allen Carrion, "Very fast money: High-frequency trading on the NASDAQ" (2013) 16 J. Financial Mark. 680; Peter Gomber et al., High-Frequency Trading, report commissioned by Deutsche Börse Group (March 2011), p. 59; Joel Hasbrouck/Gideon Saar, "Low-latency trading" (2013) 16 J. Financial Mark. 646; Terrence Hendershott/Charles Jones/Albert Menkveld, "Does Algorithmic Trading Improve Liquidity?” (2011) 66 J. Fin. 1. Overviews of the literature are given by Gaia Balp/Giovanni Strampelli, "Preserving Capital Markets Efficiency in the High-Frequency Trading Era” (2018) 2018 U. Ill. J.L. Tech. \& Pol’y 349, 356-364; Gianluca Piero Maria Virgilio, "High-frequency trading: a literature review” (2019) 33 Financial Mark. Portf. Manag. 183. 
process, for example through so-called circuit breakers that seek to curb volatility if price changes exceed pre-defined levels, has been found to be often counterproductive and to entail unintended consequences, such as volatility spillovers into other markets. ${ }^{12}$

This paper argues that much of the current regulatory framework continues to be centred around the classical disclosure paradigm of securities regulation, and hence around the role of information in financial markets, without taking sufficient account of the changes in the process of price discovery brought about by the rise of automated trading. ${ }^{13}$ Regulation based on the disclosure paradigm, which can be traced back to the US Securities Act of 1933 and Securities Exchange Act of 1934, has been credited with enhancing liquidity and reducing volatility. ${ }^{14}$ However, new challenges have arisen in modern digital capital markets. Information no longer simply contributes to the formation of fundamentally efficient prices ${ }^{15}$ through the "wisdom of crowds", but it does so increasingly often in circumstances where an algorithm is interposed between the "crowds" (informed investors) and the process of price formation. This can lead to distortions, especially where algorithms are executed so quickly that it is difficult to identify unintended consequences in real time and intervene accordingly. For example, as in the flash crash of 2010, algorithms may trigger dynamics that move prices within seconds increasingly further away from an equilibrium representing fundamental value.

The paper makes two contributions. First, methodologically, it suggests that the disclosure paradigm of securities regulation of the pre-automation age should be enriched with an account of the mechanics of price formation at the microstructure level of securities markets. This means that regulation needs to appreciate how, for example, the configuration of the limit order book, the matching algorithm used by a marketplace, or the operation of an execution, market making, or arbitrage algorithm deployed by an investment firm affect market dynamics and by extension the efficient market paradigm. The

12 The effects of circuit breakers will be discussed in detail in section 3.2.2 below.

13 A similar observation has been made in the economic literature, for example Kirilenko/Lo (fn. 6), 52, but less so in legal scholarship.

14 An important early study identifying a reduction in the dispersion of abnormal returns (i.e., a reduction in issue-specific risk), rather than in increase in mean returns, as the main effect of the Securities Act of 1933 is Carol J. Simon, "The Effect of the 1933 Securities Act on Investor Information and the Performance of New Issues”(1989) 79 Am. Econ. Rev. 295. For an overview of the debate, see John Armour et al., Principles of Financial Regulation (OUP 2016), 164.

15 Prices are fundamentally efficient if they rationally reflect fundamentals, Lawrence $\mathrm{H}$. Summers, "Does the Stock Market Rationally Reflect Fundamental Values?" (1986) 41 J. Fin. 591, 592. 
paper draws on market microstructure theory ${ }^{16}$ to illustrate how certain economic concepts that describe the operation of modern, mostly automated capital markets, for example the relationship between order volume, execution speed and price impact, can be used to assess the effectiveness of regulation. Such a discussion is largely absent from the legal literature. ${ }^{17}$ Second, against the backdrop of market microstructure theory, the paper critically reflects on current regulatory tools concerning algorithmic and high frequency trading. It argues that the empirical support for regulatory intervention (other than in the case of manipulative behaviour ${ }^{18}$ ) is weak and policy makers should, therefore, proceed with caution. In particular, circuit breakers, as currently calibrated, are likely to overreach and impede efficient price discovery by restricting price movements that represent fundamental volatility.

The remainder of this paper is structured as follows. Section 2 discusses the operation of typical algorithmic trading strategies and reviews the findings of market microstructure research in order to assess whether, and when, algorithms disrupt orderly market operations. Section 3 draws normative lessons from the technical discussion in section 2. It focuses on three central regulatory strategies: disclosure obligations and organisational requirements imposed on investment firms engaged in HFT, trading halts when price movements exceed specified thresholds, and the design of the matching mechanism used by a market. It explores whether market quality is negatively affected because trading is automated and/or executed at high frequency and discusses whether the risks to which automated trading gives rise are adequately addressed by current regulation, considering the available empirical evidence. ${ }^{19}$ Section 4 concludes.

16 Foundational works in market microstructure theory include Maureen O'Hara, Market Microstructure Theory (Blackwell 1995) and Joel Hasbrouck, Empirical Market Structure (OUP 2007). 17 Notable exceptions include Balp/Strampelli (fn. 11); Merritt B. Fox/Lawrence R. /Gabriel V. Rauterberg, Naked Open-Market Manipulation and Its Effects in Mattli (fn. 1), 199; Yadav (fn. 3 and 8); Yesha Yadav, Algorithmic Trading and Market Regulation in Mattli (fn. 1) 232; Yesha Yadav, "The Failure of Liability in Modern Markets" (2016) 102 Va. L. Rev. 1031.

18 Algorithmic trading techniques that satisfy the definition of market manipulation, such as quote stuffing, layering and spoofing, or "pump and dump", and possible regulatory responses to these techniques, are outside the scope of this paper.

19 For example, a flash crash may be caused by the manual submission of a large order or by the execution of an algorithm that submits a number of child orders in short succession that deplete liquidity, see the simulation by Paul Brewer/Jaksa Cvitanic/Charles R. Plott, "Market Microstructure Design and Flash Crashes: A Simulation Approach” (2013) 16 J. Appl. Econ. 223. Regulatory strategies that target only algorithmic or high-frequency trading, such as the increased regulatory requirements imposed by MiFID II (see sections 3.1 and 3.2), are justified if certain features of automated trading make the occurrence of a flash crash more likely and regulation develops an effective response to these features. 


\section{Algorithmic Trading and Unintended Consequences}

\subsection{Types of Trading Algorithm}

Algorithms are pervasive in modern financial markets. According to their function, they can be broadly grouped into market making algorithms, arbitrage or directional trading algorithms, and execution algorithms. Market making algorithms serve to provide liquidity, arbitrage algorithms seek to exploit market inefficiencies or price fluctuations around news announcements, and execution algorithms are used to minimise the market impact of a large trade by splitting the trade into several so-called "child orders" that are executed according to certain criteria.

Market makers provide liquidity by posting limit buy and limit sell orders. In doing so, they incur inventory risk, that is, the risk of posting a limit buy order in a downward trending market and a limit sell order in an upward trending market, and the risk that the market maker's limit orders are matched with orders of better informed traders. ${ }^{20}$ Market making algorithms make use of different parameters to manage these risks, including the number of ticks away from the market price at which limit orders are placed, possibly as a function of volatility (given that limit orders that are further away from the market price are more likely to be executed in high-volatility conditions than in low-volatility conditions), the fact that a market is trending or mean-reverting, the level of liquidity in a market, and order flow (the difference in trade volume between buyer-initiated and seller-initiated trading activity, which has been shown to become directional while news is impounded into market prices $\left.{ }^{21}\right)^{22}$

Arbitrageurs and information traders seek to exploit market inefficiencies or an informational advantage. Algorithms used by them may thus be based on models to calculate the fundamental value of a security and identify deviations from that value or deviations in price levels of correlated financial instruments or baskets of financial instruments. ${ }^{23}$ Other algorithms exploit the fact that news announcements are often not, or only partially, incorporated into prices in-

20 Irene Aldridge, High-frequency trading: A practical guide to algorithmic strategies and trading systems (Wiley, $2^{\text {nd }}$ ed. 2013), 167.

21 Ryan Love/Richard Payne, "Macroeconomic News, Order Flows, and Exchange Rates” (2008)

43 J. Financ. Quant. Anal. 467.

22 Aldridge (fn. 20), 168-192.

23 Ibid. at 131-144. 
stantaneously, and will only be fully incorporated via the order flow. ${ }^{24}$ Such algorithms may, for example, estimate likely price responses to particular types of news based on historical data and trade directionally before the market can reach a new equilibrium price level. ${ }^{25}$

Finally, execution algorithms are used to offload large positions. Typical execution algorithms are Time-Weighted Average Price (TWAP), Volume-WeightedAverage-Price (VWAP) and participation or Percentage-of-Volume (POV) algorithms. The three types of execution algorithm have in common that they split a large order into several smaller child orders to minimise the market impact of the sale. The simplest execution algorithm is TWAP, which breaks up a large order into child orders of equal size that are placed at equal time intervals in the market. ${ }^{26}$ In contrast to TWAP, in a VWAP algorithm, the size of child orders is a function of the average volume traded in the instrument during the same time of the trading day (using historical trading data, for example, from the preceding month), on the assumption that intraday volume patterns are persistent and predictable. The size of child orders is larger when historical trading volume is higher, and smaller when it is lower, which allows for a more cost-effective execution of the orders. ${ }^{27}$ Participation (POV) algorithms differ from VWAP algorithms in that they calculate the size of child orders as a percentage of the total volume traded over a specified time interval preceding the execution of each child order, rather than based on historical averages.

The large market movements during the flash crash of 2010 have been ascribed to a feedback loop caused by a POV algorithm that was used by a "fundamental trader", ${ }^{28}$ Waddell \& Reed, to unwind a large position in S\&P 500 futures ("E-Mini") contracts, and contemporaneously trading HFTs. ${ }^{29}$ The POV algorithm sent orders into the market representing $9 \%$ of the trading volume calculated

24 Love/Payne (fn. 21).

25 Aldridge (fn. 20), 148.

26 Ibid. at $253-254$.

27 Ibid. at 254-257.

28 CFTC/SEC (fn. 5), 2 define "fundamental traders" as "market participants who are trading to accumulate or reduce a net long or short position".

29 Kirilenko/Lo (fn. 6), 58; Didier Sornette/Susanne von der Becke, "Crashes and High Frequency Trading: An evaluation of risks posed by high-speed algorithmic trading”, UK Government Foresight Project, The Future of Computer Trading in Financial Markets, Foresight Driver Review DR 7 (2012), 11; Jean-Pierre Zigrand, "Feedback effects and changes in the diversity of trading strategies”, UK Government Foresight Project, The Future of Computer Trading in Financial Markets, Foresight Driver Review DR 2 (2012), 4, 8. For a detailed discussion of algorithmic trading and feedback loops, see Government Office for Science, Foresight: The Future of Computer Trading in Financial Markets, Final Project Report (2012), 61-85. 
over the previous minute, without containing any further conditions with regard to price or time, selling Waddell \& Reed's position in E-mini contracts rapidly within 20 minutes. ${ }^{30}$ This alone would not have been enough to trigger the flash crash, but other traders reacted to the POV algorithm by quickly reselling the contracts initially sold by Waddell \& Reed. The volume effects of the POV algorithm thus did not dissipate, but became self-reinforcing, exerting ever greater pressure on the sale side of the order book. ${ }^{31}$

A participation algorithm is a dynamic trading strategy, since each child order depends on the evolution of market conditions during a specified time interval before the next child order is executed, for example the previous minute. In contrast, static trading strategies are completely determined based on past market information before the strategy is executed..$^{32}$ Examples of static execution algorithms are TWAP and VWAP. Dynamic strategies such as POV have been criticised for giving rise to selling pressure and depleting liquidity, and thus meriting regulatory attention. ${ }^{33}$ However, whether they have detrimental consequences that are different from the consequences that arise whenever a large order is submitted depends on the precise structure of the algorithm and its interaction with other trading strategies. In principle, dynamic strategies, just as static strategies, do not destabilise the market if they are properly coded. The next section illustrates this point by evaluating the price effects of a typical execution algorithm that splits a large order into several child orders.

\subsection{Price Effects}

It is empirically well established that the execution of a metaorder (a large order divided into several child orders, as in a POV or VWAP algorithm) has a market impact that follows certain regularities, referred to as the "square root impact

30 CFTC/SEC (fn. 5), 2.

31 See CFTC/SEC (fn. 5), 3: "[L]acking sufficient demand [for the sell orders of Waddell and Reed] from fundamental buyers or cross-market arbitrageurs, HFTs began to quickly buy and then resell contracts to each other - generating a 'hot-potato' volume effect as the same positions were rapidly passed back and forth." See also Albert J. Menkveld/Bart Zhou Yueshen, "The Flash Crash: A Cautionary Tale About Highly Fragmented Markets" (2019) 65 Manag. Sci. 4470; Zigrand (fn. 29), 8.

32 Aldridge (fn. 20), 252.

33 Riccardo Cesari/Massimiliano Marzo/Paolo Zagaglia, "Effective Trade Execution" in H. Kent Baker/Greg Filbeck (eds.), Portfolio Theory and Management (OUP 2013), 411, 422. 
law". ${ }^{34}$ The square root law models the price impact $I$ of a metaorder of quantity $Q$ that is executed over a time horizon $T$ as follows: ${ }^{35}$

$$
I=Y \sigma_{T}\left(\frac{Q}{V_{T}}\right)^{\delta}
$$

where $Y$ is a numerical coefficient that varies depending on the security in question, $\sigma_{T}$ is volatility (standard deviation) over the same time horizon $T, V_{T}$ is the total volume of the instrument traded over $T$, and $\delta$ is a parameter that can be shown to be close to 0.5 (hence, the name "square root law") for values of $Q \ll V_{T} \cdot{ }^{36}$ If the last condition holds and the size of the metaorder is significantly smaller than the total traded volume, the impact of the child orders is therefore not additive, but decreases in $Q .{ }^{37}$ It should also be noted that $I$ is not dependent on $T$, and it is consequently, in principle, irrelevant whether the algorithm is executed over a short or a long period of time. However, importantly, $I$ is dependent on contemporaneous volatility and volume. Where $Q \ll V_{T}$ does not hold, the market impact of the metaorder depends, crucially, on the execution schedule. If execution is sufficiently slow, impact remains a concave function of $Q$, but where child orders are submitted too quickly for the order book to refill, the function becomes convex. ${ }^{38}$ This may have occurred during the flash crash of 2010. As mentioned, Waddell \& Reed used an algorithm that was designed to sell $9 \%$ of the currently traded volume, which is below the threshold where empirical studies indicate that $Q \ll V_{T}$ no longer holds. ${ }^{39}$ However, the sell orders were executed in an unusually short period of time. Initial liquidity provided by the buyers of the E-mini contracts, mostly HFTs and intermediaries, quickly dissipated as the buyers sought to reduce their long positions and accordingly also entered sell orders. ${ }^{40}$ The CFTC and SEC investigation into the flash crash concluded that the combined selling efforts of the algorithm and the HFTs and

34 For references, see Jean-Philippe Bouchaud/Julius Bonart/Jonathan Donier/Martin Gould, Trades, Quotes and Prices: Financial Markets under the Microscope (CUP 2018), 243-244; Bence Tóth/Yves Lemperiere/Cyril Deremble/Joachim de Lataillade/Julien Kockelkoren/Jean-Philippe Bouchaud, "Anomalous Price Impact and the Critical Nature of Liquidity in Financial Markets” (2011) 1 Physical Review X 021006.

35 This formulation of the square root law is from Bouchaud et al., Ibid. at 234.

36 The precise value seems to vary with tick size, Ibid. at 235.

37 For an economic explanation see Ibid. at 236.

38 A more detailed discussion of these dynamics can be found Ibid. at 237-238.

39 It has been suggested that $I$ is a concave function of $Q$ if $Q / V_{T} \leqslant 0.1$, Ibid. at 238 .

40 CFTC/SEC (fn. 5), 14-16. 
intermediaries almost completely depleted buy-side market depth in the E-Mini, which had fallen to less than $1 \%$ by the time the algorithm had sold E-Minis for about 15 minutes, compared to the same morning. As a result of the vanishing buy-side liquidity, prices dropped rapidly until the circuit breaker of the Chicago Mercantile Exchange was triggered. ${ }^{41}$

How does the price impact of a metaorder-that is, a sequence of orders typically entered by an algorithm-compare with the impact of a single order of the same size that is entered manually? As before, a substantial amount of empirical work indicates that the relationship between market impact and the size of an order is not linear, but concave. Impact as a function of the volume traded, accordingly, takes a similar form to equation (1) above. Parts of the literature have argued that the empirical evidence supports the following relationship:42

$$
I=Y \bar{s}_{t}\left(\frac{V}{\bar{V}_{\text {best }}}\right)^{\delta}
$$

As in (1), $Y$ is a numerical coefficient that depends on the asset class and $\delta$ is a parameter that varies with tick size. The volume of the submitted order $v$ is normalised by the average volume at the opposite side best quote $\bar{V}_{\text {best }}$ and $\bar{s}_{t}$ is the average spread over a small time interval just before the arrival of the order. The parameter $\delta$ has been found to be smaller than $0.5 .^{43}$ (2) is therefore more strongly concave than (1), and market impact approximates a constant with $I=Y \bar{S}_{t}$ for small-tick stocks where $\delta \cong 0$ (in other words, the market impact of orders concerning small-tick stocks tends not to be dependent on volume). Figure 1 depicts the association between market impact and volume for different parameter values of $\delta$.

It has been argued that the strong concavity of the impact response function of a single market order is partly the result of a conditioning effect. The probability density of the ratio of order volume and volume at the opposite side best quote at the time of order arrival is highest where $v / V_{\text {best }}=1$ (and, surprisingly, it generally spikes where the ratio equals a simple fraction or round number, for example 0.5 or 2). ${ }^{44}$ This means that traders often submit orders that equal the available volume at the best quote (so-called selective liquidity taking). It is rare to find orders that exceed the available volume, and somewhat less rare

41 Ibid. at 15.

42 Bouchaud et al. (fn. 34), 217.

43 Ibid.

44 Ibid. at 218-219. 


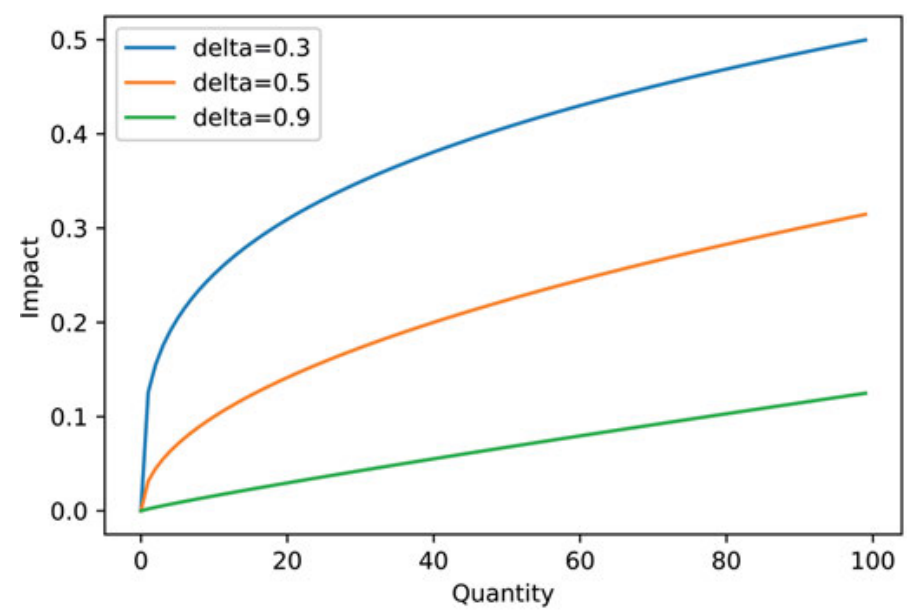

Figure 1: Market Impact as a Function of Order Volume.

Figure 1 shows the price impact of a metaorder according to the square root impact law for different values of $\delta$. $Q$ is defined so that the condition $Q \ll V_{T}$ holds after full execution of the metaorder, with the total volume of the metaorder equalling $0.1^{\star} \mathrm{V}_{\mathrm{T}} . \mathrm{Y}$ and $\sigma_{\mathrm{T}}$ are both assumed to equal 1 . It can be seen that price impact increases linearly with $\delta$ close to 1 , and the impact function becomes more strongly concave with smaller $\delta$.

to find orders that are smaller than the available volume (thus, the probability density for $v / V_{\text {best }}<1$ is greater than for $v / V_{\text {best }}>1$, but smaller than for $v / V_{\text {best }}=1$ ). If all traders submitted orders that matched exactly the volume at the best quote, the price would go up or down accordingly and market impact would be independent of order volume (disregarding any second order market effects, such as trades induced by the information content of the initial order). The relationship is not strictly constant because some orders are larger than the volume at the best quote and move the price by more than one tick and some orders that do not match the volume at the best quote may still have an impact on the market owing to their information content. Furthermore, as mentioned, there is empirical evidence that the relationship is less strongly concave for large-tick stocks than small-tick stocks (that is, $\delta$ is larger for large-tick stocks). This has been attributed to the fact that the bid-ask spread (the difference between the highest price among buy limit orders and the lowest price among sell limit orders) is typically equal to the minimum possible size of one tick in the case of a large-tick stock, but wider in the case of a small-tick stock. Hence, for large-tick stocks, price moves require that the volume on one side of the order book is completely depleted, which is more likely if the avail- 
able volume is comparatively small..$^{45}$ On the other hand, for small-tick stocks, both orders that deplete the available volume and orders with a limit price falling inside the spread move the market (i.e., the mid-price), thus making it more likely that an order has an impact irrespective of its size. ${ }^{46}$

It is not well understood why the impact response function changes for metaorders, where, as discussed, $\delta$ takes a value of approximately 0.5 , or indeed why the impact of metaorders is not a linear function of their size, as intuition may suggest. Several explanations have been suggested in the literature. For example, it has been argued that the square root law follows from the distribution of the size of metaorders and certain assumptions of how informed traders set prices, ${ }^{47}$ the assumption that traders seek to maximise their payoff from trading subject to a desired time to execution, ${ }^{48}$ or the fact that liquidity decays linearly around the current price in continuous-time double-auction markets, which results in a square root impact of orders after integration of the supply and demand curves. ${ }^{49}$ None of these explanations is undisputed, but the important point is that the empirical fact that they seek to explain-the square root impact law-has, within the law's domain of application, ${ }^{50}$ been corroborated by a large number of studies in different contexts. ${ }^{51}$

From a normative perspective, the empirical findings direct attention to two considerations. First, to reiterate, if the square root law applies, the marginal impact of a metaorder does not increase, but decreases in size. As discussed above, it is a precondition for the application of the law that the size of a metaorder is significantly smaller than the total volume traded over the time horizon of the execution of the order. That this must be so is intuitive. If the size of a child order is so large that it consumes much of the available volume on the opposite side of

$45 \mathrm{Ibid}$. at 118, 217. See also figure 11.4, Ibid. at 219, showing that an average-size order equals about $30 \%$ of the available volume if that volume is of average size, but almost all if it is unusually small, say $10 \%$ of the average volume at the best quote, and only $20-25 \%$ if it is unusually large, say twice the size of the average volume at the best quote. In other words, average order size does not grow linearly, but sub-linearly, in available volume. Smaller orders consume, on average, a higher proportion of the available volume than larger orders consume of the correspondingly larger available volume.

46 Ibid. at 118.

47 J. Doyne Farmer/Austin Gerig/Fabrizio Lillo/Henri Waelbroeck, "How efficiency shapes market impact” (2013) 13 Quant. Finance 1743.

48 Xavier Gabaix/Parameswaran Gopikrishnan/Vasiliki Plerou/H. Eugene Stanley, "A Theory of Power-Law Distributions in Financial Market Fluctuations" (2003) 423 Nature 267.

49 Tóth et al. (fn. 34), 021006-1.

50 See text to notes 36-41.

51 See fn. 34 above. 
the order book, the impact of subsequent child orders is increasing, not decreasing. ${ }^{52}$ Destabilising effects of an algorithm executing a sequence of orders are therefore not a function of the size of the orders individually or in aggregate as such, but of the available volume in the order book. The latter, in turn, is affected by the speed of execution of the metaorder. If the order book is given sufficient time to refill, an algorithm such as POV or VWAP, on its own, does not entail price dynamics that could result in a flash crash. ${ }^{53}$ Therefore, the focus of regulation should be on slowing down trading, rather than halting it altogether. ${ }^{54}$

The second important point is that the main risk of the emergence of price dynamics without stable fixed points results generally from the interaction effects of two or more algorithms, rather than the operation of an algorithm in isolation. ${ }^{55}$ Regulation should therefore be designed so that interaction effects can be assessed, and harmful effects identified. This can be achieved through the provision of appropriate testing environments and transparency. This regulatory strategy is discussed in section 3.1 below.

\section{Regulatory Solutions}

In the following sections, three central regulatory strategies will be presented and their effectiveness critically evaluated in light of the technical discussion in section 2: transparency and internal control requirements imposed on invest-

52 Impact becomes a convex function of size, see text to fn. 38 above.

53 The orders executed by the algorithm may, of course, result in a significant price drop, but if this is a result of genuine buy and sale interests and not merely a mismatch in execution speed between orders on the two sides of the order book, there is no reason for regulatory intervention. In this case (and under the assumption of rational behaviour on the part of market participants), the price drop would reflect the market's assessment of the issuer's fundamentals, and regulatory intervention would distort the process of efficient price formation.

54 A suspension of automatic order execution, followed by a call auction after several minutes, is technically similar to mechanisms suggested in the literature to slow down trading. These mechanisms rely on a call market where orders that arrive during specified time intervals are collected, priority ordered according to price and executed at the price that maximises the volume that can be traded, see e.g., Brewer et al. (fn. 19), 239-240. Thus, the process of order execution is the same under both approaches. The difference is the time interval over which orders are collected. Conventional circuit breakers halt trading for several minutes (see section 3.2.1: typically, 5 or 10 minutes), whereas a call market may use intervals as short as a few seconds or fractions of a second, see the simulation in Brewer et al. (fn. 19), 241 and Budish et al. (fn. 7) (suggesting that the continuous limit order book should be replaced with uniform price double auctions conducted every tenth of a second).

55 See the discussion of the flash crash in the text to nn 39-41 above. 
ment firms engaged in algorithmic and high-frequency trading; order resting times or delays in the processing of orders when price movements exceed specified thresholds (circuit breakers); and the design of the matching mechanism used by a market. It will be seen that many of these strategies are not well calibrated and are either too far-reaching and ineffective, or not sufficiently farreaching.

\subsection{Disclosure and Internal Risk Control Systems}

Current European regulation, laid down in MiFID II, requires investment firms that engage in algorithmic trading to "have in place effective systems and risk controls ... to ensure that its trading systems are resilient and have sufficient capacity, are subject to appropriate trading thresholds and limits and prevent the sending of erroneous orders or the systems otherwise functioning in a way that may create or contribute to a disorderly market." ${ }^{56}$ The systems must be fully tested and properly monitored. ${ }^{57}$ The competent authorities of the firm's home Member State and the trading venue(s) at which the firm engages in algorithmic trading must be notified of the fact that the investment firm employs algorithmic trading strategies. ${ }^{58}$ The home state authority "may require the investment firm to provide, on a regular or ad-hoc basis, a description of the nature of its algorithmic trading strategies, details of the trading parameters or limits to which the system is subject, the key compliance and risk controls that it has in place ... and details of the testing of its systems", and it may request further information about the firm's algorithmic trading and systems. ${ }^{59}$ The competent authorities of the trading venues where the algorithmic trader operates can request that the disclosed information be communicated to them by the home Member State regulator. ${ }^{60}$ Additional record-keeping requirements apply to high-frequen-

56 MiFID II, Art 17(1). The requirements have been implemented by Commission Delegated Regulation (EU) 2017/589 of 19 July 2016 supplementing Directive 2014/65/EU of the European Parliament and of the Council with regard to regulatory technical standards specifying the organisational requirements of investment firms engaged in algorithmic trading, [2017] OJ L87/417, Arts $1-18$.

57 MiFID II, Art 17(1).

58 Art 17(2), first subparagraph.

59 Art 17(2), second subparagraph.

60 Art 17(2), third subparagraph. 
cy traders, ${ }^{61}$ and additional organisational and operational requirements to algorithmic traders that pursue market making activities. ${ }^{62}$

It is evident that algorithmic traders should have systems in place that test and monitor their algorithms to ensure that they are correctly coded, do not send erroneous orders, or otherwise function in an unintended manner. However, if it is correct that the interaction effects of two or more algorithms are typically detrimental to market stability and efficient price discovery, rather than the price effects of an algorithm in isolation, there are limits to how well an individual firm can assess the impact of their algorithms on the market as a whole. Conventional backtesting is unsuitable to identify harmful interaction effects. Simulations that model the interaction of a firm's algorithms with other typical trading strategies are more promising, ${ }^{63}$ but there is a risk that algorithms will produce unintended consequences once they are deployed in the market and interact with idiosyncratically coded trading strategies. Testing and monitoring at the level of the investment firm, while important, ${ }^{64}$ is therefore unlikely to be sufficient.

MiFID II also requires trading venues to provide environments to facilitate the testing of algorithms, including simulation facilities that replicate the production environment and allow for the modelling of specific scenarios, for example service disruptions. ${ }^{65}$ Members must certify that they have tested their algorithms before deploying them. ${ }^{66}$ Again, it is important to recognise that the

61 MiFID II, Art 17(3), last subparagraph. The record-keeping obligations are implemented in Commission Delegated Regulation (EU) 2017/589, Art 28 and Annex II.

62 MiFID II, Art 17(3). Market making strategies are defined in Art 17(4).

63 For examples of how such a simulation could be designed, see Brewer et al. (fn. 19); Iryna Veryzhenko/Lise Arena/Etienne Harb/Nathalie Oriol "Time to Slow Down for High-Frequency Trading? Lessons from Artificial Markets” (2017) 24 Intell. Sys. Acc. Fin. \& Mgmt. 73; Nathalie Oriol/Iryna Veryzhenko, 'Market structure or traders' behavior? A multi agent model to assess flash crash phenomena and their regulation” (2019) 19 Quant. Finance 1075.

64 See, in particular, Commission Delegated Regulation (EU) 2017/589, Arts 5-7.

65 MiFID II, Art 48(6), implemented by Commission Delegated Regulation (EU) 2017/584 of 14 July 2016 supplementing Directive 2014/65/EU of the European Parliament and of the Council with regard to regulatory technical standards specifying organisational requirements of trading venues, [2017] OJ L87/350, Arts 9, 10. The provision of access to production environment simulations is required pursuant to Art 10(2). For a detailed description of one such simulation facility, the London Stock Exchange's Customer Development Service (CDS), see London Stock Exchange (LSE), MIT501 - Guide to Testing Services, Issue 20 (2020), 8-11. The CDS replicates the full market structure of the live service, simulates market activity through the interaction between customers on the service, and uses scripted scenarios to facilitate the development and testing of different routines to deal with the scenarios.

66 Commission Delegated Regulation (EU) 2017/584, Art 10(1). 
effectiveness of a trading venue's testing regime in identifying harmful consequences of an algorithmic trading strategy depends not only on an accurate replication of the venue's trading systems, but also a replication of interactions between customers comparable to what would occur on the live service. Since market maker and participant details will inevitably vary to some degree, ${ }^{67}$ disruptive effects that are a function of the interaction of two or more trading algorithms may not be captured.

Likewise, existing disclosure obligations fall short of establishing effective safeguards. First, there is no universal obligation to disclose information on trading strategies and compliance and risk control systems, but competent authorities are merely authorised to request such information, either on a regular or an ad-hoc basis. Second, the disclosed information includes details of the trading parameters, but MiFID II does not require the actual code to be disclosed. Full disclosure of algorithms to the market would certainly be resisted by algorithmic traders, for whom innovative algorithms constitute valuable trade secrets. It may also be harmful, since it would stifle financial innovation and potentially encourage herding behaviour. However, full transparency is unnecessary. If the greatest risk to stability derives from the interaction of algorithms, disclosure to the competent authority is sufficient and would allow the regulator to assess-within the limits of what is technically possible and feasible, given the available resources-the algorithms that are used in the market and their interaction effects. ${ }^{68}$ Third, MiFID II does not provide for an automatic exchange of information between competent authorities. Since algorithms, particularly arbitrage strategies, may operate on more than one market, which conforms to the aim of MiFID II to promote integrated financial markets within the EU, it is essential that the competent authorities of all affected marketplaces have full information. Indeed, in order to facilitate effective and cost-efficient supervision, and given that algorithms may target any market in the course of a trading session depending on where opportunities arise, it is counterproductive that supervision

67 See, e.g., LSE (fn. 65), 9.

68 For a similar suggestion, see Yadav (fn. 3), 1670. However, it has also been pointed out that the practical difficulties of designing an effective testing environment may be significant, because the number of possible combinations of algorithms is likely to be high and algorithms may be programmed to learn and evolve over time. For this reason, the UK Government Office for Science (fn. 29), 101-102 recommended not to adopt any notification requirements. Further research is required to explore the technical feasibility and cost-efficiency of a regulator-level notification and testing system. Nevertheless, it is important to stress that the disclosure obligations currently laid down in MiFID II are likely to impose costs on investment firms without generating commensurate benefits (this was also noted by the UK Government Office for Science (fn. 29), 101). 
(and the possible simulation of market effects) is located at the level of the Member State, rather than the EU.

\subsection{Circuit Breakers}

\subsubsection{Circuit Breakers around the World}

Most exchanges have systems in place that halt trading in individual securities or the market as a whole temporarily when certain volatility thresholds are exceeded. The US equity, options and futures exchanges have adopted two so-called national market system plans that set out their policies and procedures to mitigate high market volatility. ${ }^{69}$ Since all US exchanges participated in the formulation of the plans, uniform procedures are in place to respond to episodes of volatility concerning securities traded in the national market system. ${ }^{70}$ The first plan establishes a market wide circuit breaker (MWCB) that results in the coordinated temporary halt of all trading in equities and options on all exchanges. ${ }^{71}$ The MWCB is triggered if the S\&P 500 Index experiences a decline of $7 \%, 13 \%$ or $20 \%$ as compared to the closing price of the S\&P 500 for the immediately preceding trading day. A decline of $7 \%$ and 13\% entails a halt in trading for $15 \mathrm{mi}-$ nutes when the respective threshold is reached for the first time during a trading day, and trading is suspended for the remainder of the day if a $20 \%$ decline occurs. $^{72}$

The second plan, known as the Limit Up/Limit Down (LULD) Plan, is intended to prevent trades in securities from occurring outside of specified price bands. ${ }^{73}$ If the national best offer equals the lower price band or the national

69 National market system plans are formulated by two or more national stock exchanges and filed with the SEC for approval under Rule 608 of Regulation NMS.

70 The securities that are covered are defined in Rule 600(b)(47) of Regulation NMS.

71 The plan was first approved by SEC Release No. 34-67091, Order Approving, on a Pilot Basis, the National Market System Plan to Address Extraordinary Market Volatility, May 31, 2012. For the most recent amendments, see SEC Release No. 34-88406, Notice of Filing of the Twentieth Amendment to the National Market System Plan to Address Extraordinary Market Volatility, March 17, 2020; and SEC Release No. 34-88704, Order Approving the Twentieth Amendment to the National Market System Plan to Address Extraordinary Market Volatility, April 21, 2020.

72 See, for example, New York Stock Exchange, Rule 7.12.

73 Approved by the same release as the MWCB, SEC Release No. 34-67091 (fn. 71). For information on the operation of the plan, see Limit Up/Limit Down, Annual Report for 2019 of the Op- 
best bid ${ }^{74}$ equals the upper price band (the security enters a so-called limit state) and the limit size quotations are not executed or cancelled in their entirety within 15 seconds (because bids remain below the lower band or offers above the upper band), the primary listing exchange ${ }^{75}$ declares a five-minute trading pause, which halts trading in the security on all venues. ${ }^{76}$ If the national best bid is below the lower band but the national best offer is above the lower band, or the national best offer is above the upper band and the national best bid is below the upper band (a so-called straddle state), the primary listing exchange has discretion to declare a trading pause if it deems trading in the security to deviate from normal trading characteristics. ${ }^{77}$ After the trading pause, trading is reopened in the usual manner, ${ }^{78}$ that is, with a call auction. ${ }^{79}$ In addition to pausing continuous trading in a security that is in a limit (and potentially a straddle) state, exchanges will reprice sell orders that are below the lower band and buy orders above the upper band to the respective limit price band (but not buy orders below the lower band or sell orders above the upper band, which are non-executable since they are outside the price bands and may result in a limit or straddle state). ${ }^{80}$ Figure 2 visualises the limit and straddle states and the repricing of orders below or above the price bands.

In the EU, MiFID II requires regulated markets to be able to halt trading "if there is a significant price movement in a financial instrument on that market or a related market during a short period" ${ }^{81}$ MiFID II and the relevant implementing legislation do not specify the operational details of trading halts, but impose

erating Committee of the Plan to Address Extraordinary Market Volatility, available at http:// www.luldplan.com.

74 National best bid and national best offer are defined in Rule 600(b)(43) of Regulation NMS. 75 The primary listing exchange is the exchange on which the security has been listed the longest, Plan to Address Extraordinary Market Volatility Submitted to the Securities and Exchange Commission pursuant to Rule 608 of Regulation NMS under the Securities Exchange Act of 1934, $20^{\text {th }}$ Amendment Version (2020), Section I(O).

76 Plan to Address Extraordinary Market Volatility, Section VII(A). The price bands are calculated by adding and subtracting between $5 \%$ and $20 \%$ depending on type of security and previous closing price to a reference price, which equals the arithmetic mean price of transactions over the last five minutes. The reference price is updated every 30 seconds, provided a new reference price is at least $1 \%$ away from the current reference price, Plan to Address Extraordinary Market Volatility, Section V and Appendix A.

77 Plan to Address Extraordinary Market Volatility, Section VII(A)(2).

78 Ibid. at Section VII(B)(1).

79 See, for example, New York Stock Exchange, Rules 7.11(b), 7.35, 7.35(A).

80 See, for example, Ibid. Rule 7.11(a)(5).

81 MiFID II, Art 48(5), first subparagraph; Commission Delegated Regulation (EU) 2017/584, Art 18(1)(b). 
Limit state

Lower band: 10 Upper band: 12

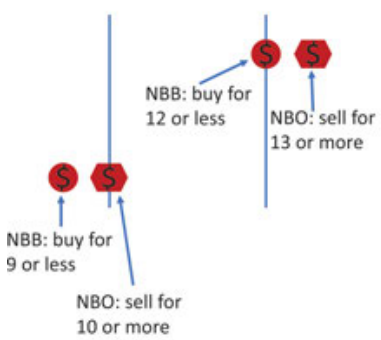

Straddle state

Lower band: 10 Upper band: 12
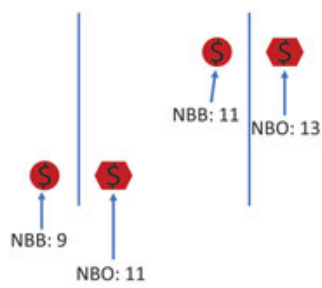

Repricing

Lower band: 10 Upper band: 12

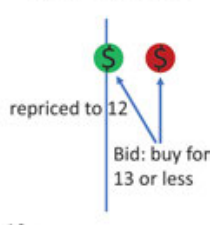

Figure 2: Limit and Straddle States; Repricing of Orders (US law)

Figure 2 shows examples of a limit state and a straddle state on US exchanges. Note that an offer to sell below the lower price band or a bid to buy above the upper price band will be repriced to the respective band, thus resulting in a limit state if the national best bid is also below, or the national best offer above, that price band.

an obligation on trading venues to test their circuit breakers before implementation and periodically thereafter, continuously monitor them, and allocate IT and human resources to the design, maintenance and monitoring of the circuit breakers. ${ }^{82}$ ESMA has developed common standards that are "to be taken into consideration by trading venues for the calibration of their circuit breakers and ... to ensure consistent application of the provisions" of MiFID II. ${ }^{83}$ Criteria set out by the guidelines include the nature and liquidity profile of the financial instrument (with tighter parameters applying to more liquid instruments), trading mode (with tighter parameters applying in the case of continuous auctions and quote driven systems), and type of reference price (stipulating that both a static and a dynamic reference price should be used). ${ }^{84}$ Otherwise the design of circuit breakers is within the discretion of the trading venue.

MiFID II seeks to achieve the necessary coordination across trading venues by requiring a venue that is "material in terms of liquidity" 85 in the respective

82 Commission Delegated Regulation (EU) 2017/584, Art 19(2).

83 ESMA, Guidelines on calibration of circuit breakers and publication of trading halts under MiFID II, 6 April 2017, ESMA70 - 872942901-63, para 6.

84 Ibid. at paras 11-13.

85 Material market in terms of liquidity is, for shares, depositary receipts, exchange-traded funds, certificates and similar financial instruments, the trading venue with the highest turnover within the Union for that financial instrument, and for other financial instruments the regulated market where the financial instrument was first admitted to trading, Commission Delegated Reg- 
financial instrument to notify competent authorities of a trading halt so that they can devise "a market-wide response and determine whether it is appropriate to halt trading on other venues on which the financial instrument is traded". ${ }^{86}$ This is in clear contrast to the US approach, which, as discussed, relies on a national market system plan formulated by the US exchanges to provide for coordinated cross-market trading halts.

To give a few examples from Europe, the London Stock Exchange monitors whether the price of a potential execution remains within a range equalling a predetermined percentage above and below the last order book execution price or the most recent auction price from the current day. ${ }^{87}$ The applicable thresholds depend on the type of security and segment on which it is traded. ${ }^{88}$ If a security breaches a price monitoring threshold, automatic execution is suspended for five minutes and a call auction is held to allow for the formation of a reliable price. Should the auction fail to generate a price that is within applicable tolerance levels around the dynamic reference price, the call period is extended by another five minutes. After this additional extension period, orders will be matched to the extent possible and executed irrespective of price monitoring tolerance levels. ${ }^{89}$ The Frankfurt Stock Exchange and the Euronext markets rely on similar mechanisms involving price bands around a dynamic and a static reference price and the suspension of continuous trading, followed by a call auction, if the price bands are breached.

While the basic design of circuit breakers is thus comparable on the three exchanges, the circuit breakers operate according to different parameters, which can result in conflicting responses to market volatility. On Euronext, the price monitoring bands applicable to equities range from $3 \%$ to $10 \%$, while

ulation (EU) 2017/570 of 26 May 2016 supplementing Directive 2014/65/EU of the European Parliament and of the Council on markets in financial instruments with regard to regulatory technical standards for the determination of a material market in terms of liquidity in relation to notifications of a temporary halt in trading, [2017] OJ L87/124, Art 1.

86 MiFID II, Art 48(5), second subparagraph.

87 London Stock Exchange (LSE), MIT201 - Guide to the Trading System, Issue 15 (2020), Sections 7.3, 7.4.

88 The thresholds are set out in London Stock Exchange, Millennium Exchange and TRADEcho Business Parameters (2020), available at https://www.londonstockexchange.com/trade/equitytrading (see tab "Sector Breakdown"). For example, for the most liquid shares included in the FTSE 100, the thresholds are $+/-8 \%$ of the static reference price (the most recent auction price) and $+/-3 \%$ of the dynamic reference price (the last order book execution price). Price bands become increasingly wider as securities are less liquIbid.

89 Ibid. (see tab "Trading Service Breakdown”). 
they are wider on the London Stock Exchange (3\% to $25 \%) .{ }^{90}$ An interruption of continuous order execution lasts at least two minutes on the Frankfurt Stock Exchange, three minutes on Euronext, and five minutes on the London Stock Exchange. ${ }^{91}$ In addition, the consequences of a breach of the price bands differ. On the Frankfurt Stock Exchange, a so-called volatility interruption is initiated if the execution price of an order would be outside either the dynamic or the static price range. ${ }^{92}$ In contrast, the Euronext markets distinguish between a breach of the dynamic and static price bands (called "collars"). Securities included in the benchmark indices of the most significant stocks on the Euronext markets, such as the CAC40, are subject to so-called collar confirmation logic. ${ }^{93}$ This means that an order that would be executed at a price outside the dynamic collars is rejected, but trading remains in continuous mode. The member can confirm the order within 30 seconds with the same price. If the confirmed order still entails a collar breach, the reference price is updated to the collar crossing price, new collars are calculated and the trade is executed, provided it is now within the updated collars. An order can be confirmed two times and, if it remains outside the collars, will then be rejected (but continuous trading is not interrupted). Other securities are not subject to collar confirmation logic, and trading will be halted (the security "reserves"94) if a matching price is outside the dynamic collars. Likewise, collar confirmation logic does not apply to breaches of the static collars, which are higher than the dynamic collars. ${ }^{95}$

Figure 3 gives an example of a dual-listed company with shares traded on both the London Stock Exchange and Euronext. As can be seen, it is possible that trading in dual-listed shares is suspended on one exchange, while it continues on the other.

90 Euronext Rule Book I (2019), Rules 4403/1, 4403/2; Euronext, Trading Manual 4-01 for the Optiq Trading Platform (2019), Section 4.2 and Appendix. The Frankfurt Stock Exchange discloses only the method for calculating the dynamic and static reference prices, but not the actual price bands, Deutsche Börse, Exchange Rules for the Frankfurter Wertpapierbörse (FWB) (2020), $\S \S 95,96$; Deutsche Börse, T7 Release 8.1: Market Model for the Trading Venue Xetra (2020), Section 9.1.

91 See above and Deutsche Börse, Trading Parameters Xetra Frankfurt (2020), available at https://www.xetra.com/xetra-en/trading/trading-models (follow hyperlink "Trading parameters \& tick sizes”); Euronext, Trading Manual 4-01 (fn. 90), Section 4.2.4.

92 Deutsche Börse, T7 Release 8.1 (fn. 90), Section 9.2.1.

93 Euronext, Trading Manual 4-01 (fn. 90), Section 4.2.1.1.

94 Ibid. at Section 3.4.2.

95 Ibid. at Section 4.2.2. Dynamic collars start at 3\% and static collars at $8 \%$ for the securities with the highest liquidity, Ibid., Appendix (see tab “Appendix to 4-01 Manual OPTQ”, columns "Col C" and "Static Col”). 


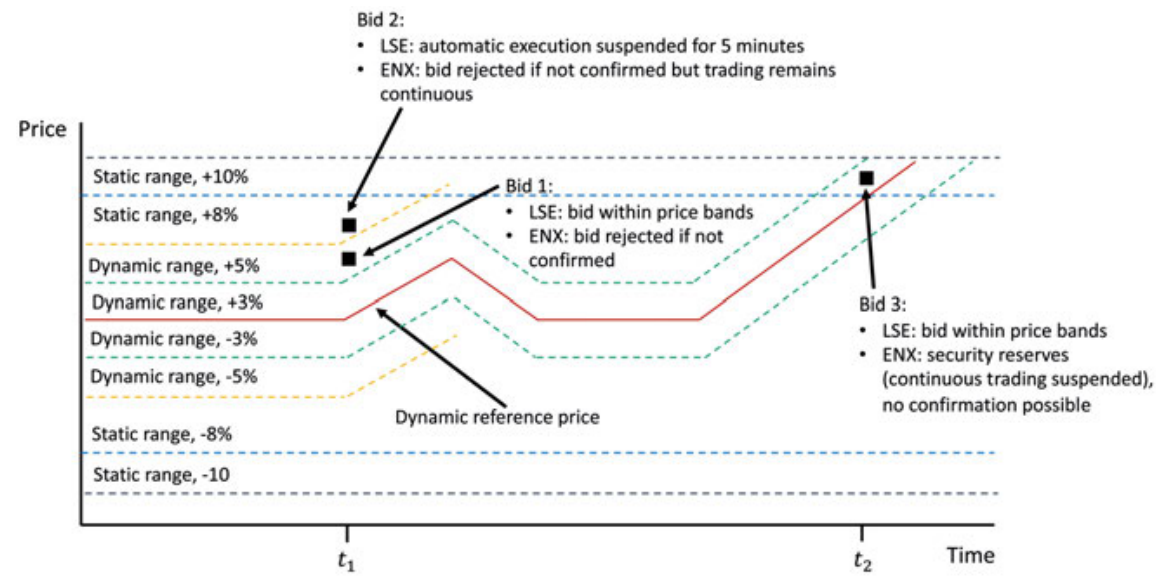

Figure 3: Volatility Bands in the UK and the EU

Figure 3 depicts three scenarios where circuit breakers are initiated idiosyncratically after the submission of identical orders to buy a dual-listed stock. For example, Just Eat Takeaway.com N.V. is listed on both Euronext Amsterdam (ENX) and the London Stock Exchange (LSE). It is a constituent company of the AEX and the FTSE 100, but does not belong to the most liquid FTSE 100 index constituents. As such, it is subject to dynamic collars of $3 \%$ and static collars of $8 \%$ on Euronext Amsterdam and a dynamic price monitoring threshold of $5 \%$ and a static threshold of $10 \%$ on the LSE. Bid 1 represents an order falling outside the dynamic ENX thresholds, but inside the dynamic LSE thresholds. Bid 2 represents an order falling outside the dynamic thresholds on both exchanges, and bid 3 an order that is inside the dynamic thresholds on both exchanges, but outside the static thresholds on ENX. Collar confirmation logic according to the Euronext rules applies to Just Eat Takeaway.com, hence neither bid 1 nor bid 2 result in a suspension of continuous trading on Euronext Amsterdam, but the bids must be confirmed and will otherwise be rejected. In contrast, collar confirmation logic does not apply to bid 3, which breaches the static collars. Consequently, a reservation period of three minutes ensues and a call auction will be held to facilitate price formation. On the London Stock Exchange, only bid 2 falls outside the price monitoring thresholds and will result in a suspension of automatic execution.

\subsubsection{Efficiency of Circuit Breakers}

The description of the operation of circuit breakers in section 3.2.1 gives rise to three related questions, which are ultimately empirical in nature. First, the case for regulatory intervention in the form of trading halts or the suspension of automatic order execution requires that it can be shown that circuit breakers have a positive effect on price discovery. Second, circuit breakers need to be calibrated carefully, both with regard to the conditions under which they are activated and the type and length of market intervention they entail. Finally, if a case in 
favour of the adoption of circuit breakers can be made, the question arises whether, and how, circuit breakers operating on different exchanges should be coordinated, in particular where financial markets are closely integrated, such as in the United States or the EU, but also between the EU and the UK or Switzerland.

\section{(1) Effects on Volatility, Liquidity and the Efficiency of Price Discovery}

The effects of circuit breakers on volatility, liquidity and price discovery are hotly debated. ${ }^{96}$ Both theoretical models and empirical studies offer mixed findings. The traditional argument in favour of circuit breakers, the so-called cooling-off hypothesis, posits that circuit breakers contribute to price stability and the efficiency of price formation by curbing overreaction and dissuade market manipulation. ${ }^{97}$ This argument builds on the empirically well supported claim that markets exhibit "excess volatility", that is, securities prices are more volatile than

96 Recent studies include Benjamin Clapham/Peter Gomber/Martin Haferkorn/Sven Panz, "Managing Excess Volatility: Design and Effectiveness of Circuit Breakers" (2017) SAFE Working Paper No. 195, available at SSRN: https://ssrn.com/abstract=2910977 (finding that circuit breakers decrease excess volatility, but also liquidity); Peter Gomber/Martin Haferkorn/Marco Lutat/Kai Zimmermann, "The Effect of Single-Stock Circuit Breakers on the Quality of Fragmented Markets" in Fethi A. Rabhi/Peter Gomber (eds.), Enterprise Applications and Services in the Finance Industry (Springer 2012), 71 (finding that a decline in market volatility after the activation of a circuit breaker comes at the cost of higher spreads and weakened price discovery in satellite markets); Cyrille Guillaumie/Giuseppe Loiacono/Christian Winkler/Steffen Kern, Market impacts of circuit breakers - Evidence from EU trading venues (2020) ESMA Working Paper No. 1, 2020 (finding that price volatility is significantly lower after the use of a circuit breaker); Zeguang Li/Keqiang Hou/Chao Zhang, "The impacts of circuit breakers on China's stock market” (2020) Pacific-Basin Finance Journal (available online) (finding that circuit breakers hinder efficient price discovery); Steven Shuye Wang/Kuan Xu/Hao Zhang, "A microstructure study of circuit breakers in the Chinese stock markets” (2019) 57 Pacific-Basin Finance Journal 101174 (finding no evidence of a reduction in market volatility or order book imbalances after market-wide circuit breakers are triggered). For an overview of the theoretical and empirical literature, see David Abad/Roberto Pascual, "Holding Back Volatility: Circuit Breakers, Price Limits, and Trading Halts" in $H$. Kent Baker/Halil Kiymaz (eds.), Market Microstructure in Emerging and Developed Markets: Price Discovery, Information Flows, and Transaction Costs (Wiley 2013), 303; Imtiaz Mohammad Sifat/Azhar Mohamad, "Circuit breakers as market stability levers: A survey of research, praxis, and challenges” (2019) 24 Int. J. Finance Econ. 1130.

97 Christopher K. Ma/Ramesh P. Rao/R. Stephen Sears, "Volatility, price resolution, and the effectiveness of price limits” in Franklin R. Edwards (ed.), Regulatory Reform of Stock and Futures Markets (Springer 1989), 67. 
predicted by the efficient markets hypothesis. ${ }^{98}$ In addition, it has been argued that trading halts encourage the provision of liquidity. ${ }^{99}$ After a halt, trading resumes with a call auction. In contrast to continuous order execution, a call auction involves the execution of all orders collected during the call period that can be matched (that is, all market orders and limit orders that can be executed at the limit price or better). The auction (or "uncrossing") price is typically the price at which the executable volume is maximised. ${ }^{100}$ Thus, call auctions reduce the risk that limit orders remain unexecuted. Suspending continuous order execution during times of high volatility, the argument goes, therefore gives an incentive to place limit orders during normal times. ${ }^{101}$

Most of the theoretical arguments, however, go both ways. The main argument against circuit breakers and other forms of trade interruptions is that trades carry informational content, and trading halts therefore delay price discovery. ${ }^{102}$ Several studies have found evidence of inefficiencies in price discovery on markets with circuit breakers, measured, for example, as deviations of stock returns from a random walk path. ${ }^{103}$ Furthermore, it is clear that circuit breakers interfere with trading strategies and interrupt execution schedules, which may result in losses for traders that could have been avoided without the interruption. ${ }^{104}$ It has also been argued that circuit breakers may have the perverse effect of increasing volatility, rather than reducing it. This can be expected both on the primary market of a security, because traders anticipate a halt in trading as the price of a security approaches the threshold at which a circuit breaker is triggered and advance their trades to ensure that they are executed before trading is paused, ${ }^{105}$ and on secondary markets without coordinated circuit breakers, be-

98 Robert J. Shiller, "Do Stock Prices Move Too Much to be Justified by Subsequent Changes in Dividends?” (1981) 71 Am. Econ. Rev. 421.

99 Sifat/Mohamad (fn. 96), 1145.

100 For an example of a call action execution algorithm, see LSE, MIT201 - Guide to the Trading System (fn. 87), Section 7.2.5.

101 See section 3.3 below for a more detailed comparison of call auctions and continuous order execution.

102 Eugene F. Fama, "Perspectives on October 1987 or What Did We Learn from the Crash" in Robert J. Barro et al. (eds.), Black Monday and the Future of Financial Markets (Irwin, 1989). 103 For an overview of the research, see Sifat/Mohamad (fn. 96), 1152-1154.

104 David M Serritella, "High Speed Trading Begets High Speed Regulation: SEC Response to Flash Crash, Rash” (2010) 2010 U. Ill. J.L. Tech. \& Pol’y 433, 441-442; Sifat/Mohamad (fn. 96), $1154-1155$.

105 Avanidhar Subrahmanyam, "Circuit breakers and market volatility: A theoretical perspective” (1994) 49 J. Fin. 237 (hereinafter "Circuit breakers and market volatility”). This phenomenon has been called the "magnet effect". Empirical evidence of the magnet effect has been found in several markets, see, e.g., Edward Curran/Vito Mollica, Magnet Effects of Price Limits: Evidence 
cause traders migrate to these markets and thus transfer price variability from the primary to the secondary markets. ${ }^{106}$ Finally, the migration of price variability to secondary markets has been shown to be accompanied by a transfer of market liquidity and trading volume in the same direction. ${ }^{107}$ Thus, if these studies are correct, there is a tension between the policy goals of reducing volatility and preserving market liquidity that is difficult to resolve with circuit breakers. In conclusion, given the absence of clear empirical support, the normative case for circuit breakers is weak.

\section{(2) Calibration of Circuit Breakers}

The previous section suggested that caution should be exercised when devising regulatory tools that interfere in the trading process. This section will discuss whether it is possible to attenuate the detrimental effects identified by empirical studies by calibrating circuit breakers appropriately. A first possibility concerns the criteria that trigger a circuit breaker. In theory, an efficient trigger would distinguish between what has been called fundamental (or permanent) and transitory volatility. ${ }^{108}$ Fundamental volatility is a function of new information concerning the fundamentals of an investment. Efficient price formation requires that such information is quickly and fully absorbed by the market. Mechanisms that reduce volatility beyond certain thresholds, therefore, impede the efficiency

from a Market Liberalization Experiment (2018), available at SSRN: https://ssrn.com/abstract $=3115844$. The fact that traders anticipate the initiation of a circuit breaker and accelerate their trades implies that discretion-based circuit breakers are preferable to circuit breakers operating with bright-line trigger points, Avanidhar Subrahmanyam, "On rules versus discretion in procedures to halt trade” (1995) 47 J. Bus. Econ. 1 (showing that discretion-based halts attenuate the magnet effect).

106 Bei Cui/Arie E. Gozluklu, "Intraday rallies and crashes: Spillovers of trading halts” (2016) 21 Int. J. Finance Econ. 472; Charles S. Morris, "Coordinating circuit breakers in stock and futures markets” (1990) 75 Federal Reserve Bank of Kansas City Economic Review 35. However, again, the empirical evidence is mixed. Benjamin Clapham/Peter Gomber/Sven Panz, "Coordination of Circuit Breakers? Volume Migration and Volatility Spillover in Fragmented Markets" (2017) SAFE Working Paper No. 196, available at SSRN: https://ssrn.com/abstract=2906719, find no evidence of volatility spillovers into satellite markets, but rather that the market share of the main market increases during a circuit breaker. For similar findings, see James Brugler/Oliver Linton/ Joseph Noss/Lucas Pedace, "The Cross-Sectional Spillovers of Single Stock Circuit Breakers" (2018) 4 Market Microstructure and Liquidity 1950008; Guillaumie et al. (fn. 96), 31-38.

107 Subrahmanyam, "Circuit breakers and market volatility" (fn. 105), 250.

108 Abad/Pascual (fn. 96), 317; Joel Hasbrouck, "Modeling market microstructure time series" in G.S. Maddala and C. Radhakrishna Rao (eds.), Handbook of Statistics 14: Statistical Methods in Finance (Elsevier 1996), 647, 648-649. 
of price discovery to the extent that market movements represent fundamental volatility and breach applicable price bands. Transitory volatility, in contrast, refers to deviations of prices from their fundamental value because of market friction, for example a lack of liquidity, manipulative trading activity, or irrational investor behaviour, such as herding or a trading strategy based on the law of small numbers. ${ }^{109}$ Reducing this form of volatility evidently enhances the efficiency of prices. The main challenge in devising an efficient circuit breaker, therefore, is to develop criteria that allow the identification of transitory volatility.

It is questionable whether volatility can be decomposed precisely into a fundamental and a transitory part. Often (albeit not always, the Black Monday stock market crash of 19 October 1987 is a famous example), transitory volatility is triggered by a change in fundamentals. Statistically, the distinction can be captured by decomposing securities prices into a random part, which represents fundamental volatility (the error term in a simple random walk model), and a stationary part, which represents transitory volatility. ${ }^{110}$ In some contexts, the random variable that represents transitory volatility is observable or can be modelled indirectly, thus allowing decomposition, in others this is not possible. ${ }^{111}$ The parameters used in current regulation are, in any case, not suitable to differentiate between fundamental and transitory volatility. ${ }^{112}$ As we have seen, circuit breakers in operation in the US and Europe employ a simple rule based on price moves over a trading day, expressed in percentage deviations from a static or dynamic reference price. ${ }^{113}$

However, even if it is not possible to decompose volatility precisely into a fundamental and a transitory part, it may be possible to identify certain patterns that are indicative of volatility occurring without a change in fundamentals. The activation of a circuit breaker could then be made conditional on the observation of such patterns. Where they are absent, a policy maker may either refrain from activating a circuit breaker altogether, given the weak empirical support for a positive effect of circuit breakers on volatility and liquidity, or impose higher thresholds in terms of percentage deviations from a reference price. The discussion in section 2 above suggests that a clear case for regulatory intervention exists when price impact changes from being a concave function of size to a convex

109 Abad/Pascual (fn. 96), 317.

110 Hasbrouck (fn. 108), 653-654.

111 An example of observable transitory volatility is the deviation from an efficient price that results from the bid-ask spread charged by market makers, see Ibid. at 654-656.

112 See, for example, ESMA, Guidelines on calibration of circuit breakers (fn. 81), 6-8.

113 Section 3.2.1 above. 
function. In this case, it is likely that two or more algorithms interact in unintended ways and price movements do not (solely) reflect fundamental volatility. For the calibration of circuit breakers, this means that dynamic or static reference price bands should be combined with other measures that capture the marginal price impact of orders over a defined period of time. Further research is required to determine the most appropriate such measures in light of price dynamics typically exhibited by flash crashes. ${ }^{114}$ As currently calibrated, circuit breakers, in any case, do not distinguish between fundamental and transitory volatility and are, therefore, likely to overreach.

A second approach to attenuating potential inefficiencies of circuit breakers could focus on the form of market intervention that ensues when a circuit breaker is triggered. As mentioned in section 3.2.1, circuit breakers in the US and Europe typically halt trading for 5 or 10 minutes. However, an analysis of the price impact of algorithms executing metaorders suggests that regulatory intervention that slows down trading is preferable to intervention that halts it altogether. ${ }^{115}$ Trading can be slowed down by switching from continuous order execution to a call auction mechanism for a limited period of time. Empirical evidence concerning the effects of switching from continuous to periodic order execution will be reviewed in section 3.3 below.

\section{(3) Coordination Issues}

Fragmented markets and interrelated assets call the effectiveness of trading halts into question if circuit breakers are not coordinated across securities exchanges and across markets within the same exchange, in particular between cash and derivative markets. This was illustrated by the flash crash of 2010, when circuit breakers were triggered on the Chicago Mercantile Exchange, where the E-Mini contracts were traded, but initially not on NYSE, where the underlying cash products were listed, leading to a mismatch in the processing of equity orders and

114 The literature has made some suggestions for identifying patterns indicative of harmful volatility, see, e.g., David Easley/Marcos M. López de Prado/Maureen O'Hara, "Flow Toxicity and Liquidity in a High-frequency World" (2012) 25 Rev. Financ. Stud. 1457 (introducing a "VPIN toxicity metric" based on volume imbalance and trade intensity); Easley/de Prado/O'Hara (fn. 5) (arguing that order flow as captured by the VPIN metric indicated high toxicity in the hours before the flash crash of 2010, which contributed to the withdrawal of liquidity during the flash crash). 115 See section 2.2. 
derivative hedges. ${ }^{116}$ Algorithms also typically reroute orders if they cannot be executed on one exchange, which may propagate volatility if circuit breakers are calibrated differently. ${ }^{117}$

Regulation NMS in the United States seeks to address these problems by institutionalising the formulation of national market system plans that provide for uniform policies and procedures to mitigate high market volatility. ${ }^{118}$ As mentioned, in response to the flash crash of 2010, all US securities exchanges adopted two such plans, one concerning a market wide circuit breaker ${ }^{119}$ and the other (Limit Up/Limit Down (LULD) Plan) individual securities that cross certain price bands. ${ }^{120}$ The LULD Plan applies to so-called NMS stocks, which comprise all NMS securities except rights and warrants. ${ }^{121}$ The relevant price bands differentiate between the most liquid ("Tier 1") securities, in particular stocks included in the S\&P 500 and Russell 1000 indices and certain exchange-traded funds, and less liquid ("Tier 2") securities, ${ }^{122}$ but they are otherwise aligned and provide for a synchronised, market-wide treatment of both derivative instruments and underlying equity and debt securities.

In the EU, in contrast, coordination across markets is, so far, limited. Following a common strategy in EU capital markets law, MiFID II imposes reporting and notification requirements on trading venues and seeks to achieve coordination at the level of market regulators. More precisely, MiFID II requires regulated markets to report the parameters for a halt in trading to their national competent authorities, which in turn report them to ESMA. ${ }^{123}$ When a circuit breaker is triggered on a market that is "material in terms of liquidity", ${ }^{24}$ the trading venue has to notify the competent authorities of the trading halt. The competent authorities will then consider whether trading should be halted on other markets.

Empirical evidence concerning the effectiveness of this system of notification and regulator-level coordination is limited. The most detailed study, an ESMA-led assessment of circuit breakers in the EU, does not address the question of coordination directly. However, for a sample of cross-listed shares, it analyses

116 Avanidhar Subrahmanyam, "Algorithmic trading, the Flash Crash, and coordinated circuit breakers" (2013) 13 Borsa Istanbul Review 4, 7. Likewise, the initial regulatory response to the Flash Crash was criticised for its limited coverage, see Serritella (fn. 104), 441.

117 See $\mathrm{n} 106$ above and accompanying text.

118 See section 3.2.1 above

119 See the references in fn. 71 above.

120 See the references in fn. 73 above.

121 Regulation NMS, §600(b)(48).

122 LULD Plan, Appendix A.

123 MiFID II, Art. 48(5), second subparagraph.

124 See fn. 85 above for a definition. 
the effect that the activation of a circuit breaker on one market has on trading activity on satellite markets. ${ }^{125}$ In a substantial number of cases, circuit breakers on satellite markets are not triggered and trading continues, but the study identifies a "hidden circuit breaker effect". As trading is halted on the primary market, trading activity and volatility also decrease on satellite markets and, as a consequence, bid-ask spreads widen. When trading resumes on the primary market, the order book refills quickly on the satellite markets and volatility increases. ${ }^{126}$ If these findings are corroborated, they imply that the response of market participants to the activation of a circuit breaker on one market achieves a de facto coordination across markets. Regulatory action, either in the form of an alignment of circuit breaker parameters similar to Regulation NMS or the adhoc extension of a trading halt to other markets, may accordingly be less important. The ESMA study also observes that an alignment of circuit breakers is difficult to implement in practice, since volatility parameters, such as price collars, will have different effects in markets that differ in terms of liquidity and other market conditions. ${ }^{127}$ Thus, it is unlikely that a simple replication of parameters would be effective. On the other hand, it should be noted that the evidence on volatility spillovers is mixed and several studies find that circuit breakers have negative effects in the absence of coordination. ${ }^{128}$ More research is required to investigate these questions and understand the comparative effectiveness of the EU and US approaches to coordination of circuit breakers.

\subsection{Auction Design}

Typically, a continuous double auction mechanism is used to trade securities on exchanges. In a double auction, buyers and sellers submit bids and offers at a particular size and price level (or at multiple price levels). The orders are time stamped and executed, usually according to priority by price and then time. ${ }^{129}$ In contrast, in a call auction, bids and offers are collected over specified intervals. At the closing of the auction, the auction platform determines a single price that maximises the volume of trades. Periodic call auctions are used at

125 Guillaumie et al. (fn. 96), 31-38.

126 Ibid. at 32-33.

127 Ibid. at 39.

128 See $\mathrm{n} 106$ above for references.

129 Thus, limit orders are ordered from highest to lowest on the buy side and lowest to highest on the sell side, irrespective of the time when they were submitted, and then matched according to time priority. 
the open and close of a market, and also when trading resumes after it was halted because a circuit breaker was triggered. ${ }^{130}$

Several studies have examined the effects of continuous double auction and call auction mechanisms on volatility and liquidity. Some have used a simulated market environment to test how extreme price movements are absorbed by markets with continuous and periodic order execution. They have found that switching from a continuous double auction to a periodic call auction, with auction call periods ranging between one second and one minute, was more effective in restoring liquidity and reducing price variability after a flash crash than halting trades. ${ }^{131}$

Other studies have gone further and suggested that frequent call auctions, conducted, for example, every tenth of a second, are generally superior to continuous order execution in the presence of high frequency trading, even if new information that affects the value of a financial instrument is symmetrically observed by all traders. ${ }^{132}$ When new information becomes publicly available, trading firms that provide liquidity to the market will seek to cancel their existing quotes and submit new quotes that reflect the updated valuation of the instrument. Simultaneously, arbitrageurs will seek to buy at the old ask before liquidity providers can adjust their quotes. In a market with a continuous limit order book, requests to cancel and orders are processed in order of receipt. Whether the liquidity providers are able to cancel before arbitrageurs buy at the now stale price therefore depends on the speed of order submission, and there is a high likelihood that liquidity providers will sell at the incorrect price at least some of the time. ${ }^{133}$ This situation gives rise to two inefficiencies. First, even in a perfectly competitive market without asymmetric information about fundamentals, the bid-ask spread will be positive in order to incorporate the cost of liquidity provision associated with the arbitrage opportunity. Second, liquidity

130 Andrew Ellul/Hyun Song Shin/Ian Tonks, "Opening and Closing the Market: Evidence from the London Stock Exchange” (2005) 40 J. Financ. Quant. Anal. 779.

131 Brewer et al. (fn. 19); Ravi Jagannathan, "On Frequent Batch Auctions for Stocks” (2020) J. Financ. Econom., nbz038.

132 Eric M. Aldrich/Kristian López Vargas, "Experiments in high-frequency trading: comparing two market institutions” (2020) 23 Exp. Econ. 322; Budish et al. (fn. 7); J. Doyne Farmer/Spyros Skouras, "Review of the benefits of a continuous market vs. randomised stop auctions and of alternative Priority Rules (policy options 7 and 12)”, UK Government Foresight Project, The Future of Computer Trading in Financial Markets, Economic Impact Assessment EIA11 (2012); Elaine Wah/Michael Wellman, "Latency Arbitrage, Market Fragmentation, and Efficiency: A Two-Market Model" in Proceedings of the Fourteenth ACM Conference on Electronic Commerce (ACM 2013) 855.

133 Budish et al. (fn. 7), 1553-1554. 
providers and arbitrageurs have an incentive to engage in a wasteful high-frequency "arms race" with the goal of reducing latency. ${ }^{134}$ It has been shown that both inefficiencies can be eliminated by processing orders in discrete rather than continuous time using uniform-price auctions. ${ }^{135}$ This strand of research has important implications for market microstructure design and regulation. Notably, it directs attention to the fact that many widely discussed pathologies of high-frequency trading are not a function of trading at high frequency as such, ${ }^{136}$ but of flawed market design. ${ }^{137}$

These two strands of research reinforce the arguments from section 3.2.2(2) above. While more work is required to better understand the relationship between the time interval between auctions, the severity of a flash crash, and the efficiency of price discovery, ${ }^{138}$ the available research suggests that current circuit breakers halt trading for inefficiently long periods of time. ${ }^{139}$

\section{Conclusion}

The traditional disclosure paradigm of securities regulation cannot give clear guidance to policy makers in the world of algorithmic and high-frequency trading, where market inefficiencies are often a result of market design, rather than informational asymmetries. This article highlights the importance of market microstructure theory as a foundation for the regulation of algorithmic and highfrequency trading. While many questions have not yet been answered conclusively, research in market microstructure theory holds important lessons that can inform the scope and type of regulatory intervention. Where the empirical evidence in support of regulatory intervention is weak, regulators should act with caution. In the absence of clear evidence, it is particularly important to calibrate regulatory mechanisms carefully and explore alternatives to traditional approaches. For example, in the case of circuit breakers, switching from continuous trading

134 Ibid. at 1554-1555.

135 Ibid. at 1597-1601.

136 As mentioned, the empirical evidence suggests that high-frequency trading generally has positive effects on market quality and price formation, see the references in $\mathrm{n} 11$ above.

137 Budish et al. (fn. 7), 1557.

138 See, e.g., Jagannathan (fn. 131), 2 (also pointing out that the consequences of switching from continuous to periodic order execution can only fully be assessed if it is well understood how different types of trader would change their trading strategies in response to periodic auctions).

139 See section 3.2.1. 
to a call auction, with a short auction call period, may be preferable to halting trading altogether. In addition, market microstructure theory draws attention to issues at the intersection of the mechanics of trading and securities regulation that warrant further research. For example, it is not well understood when algorithms interact in ways that give rise to harmful feedback loops, or how price movements that result from feedback loops can be distinguished from fundamental volatility that reflects the availability of new information. This article reviews findings in market microstructure theory and makes suggestions for refining regulatory mechanisms in order to take account of these insights, or for limiting the scope of regulation where further research is required to produce clearer evidence. 